\title{
CONNOTEA: SITE PARA A COMUNICAÇÃO CIENTÍFICA E COMPARTILHAMENTO DE INFORMAÇÕES NA INTERNET
}

\author{
Cleusa Pavan \\ Geórgia Geogletti Cordeiro Dantas \\ Ida Regina C. Stumpf \\ Sônia Elisa Caregnato
}

\section{Resumo}

A Internet é reconhecidamente um terreno fecundo para as comunidades científicas, por sua rapidez, diversidade e possibilidades de novas formas de interação. O desenvolvimento de sites de social bookmarks, como o Connotea, permite aos pesquisadores gerenciar informações na Internet, organizando e compartilhando referências com seus pares científicos. Analisa-se este site que possui um caráter social e se apresenta como um novo espaço informal para compartilhamento de informações, criação de grupos e construção de bibliotecas próprias através do emprego de palavraschave. Também, abordam-se os conceitos de comunidades científicas, social bookmarks e Folksonomia. Considera-se que o Connotea reproduz algumas tendências naturais das comunidades científicas e permite o intercâmbio entre as diferentes áreas do conhecimento.

\section{Palavras-chave:}

Comunidade Científica. Social Bookmarks. Folksonomia. Connotea.

\section{CONNOTEA: A SITE FOR SCIENTIFIC COMMUNICATION AND INFORMATION SHARING ON THE INTERNET}

\begin{abstract}
The Internet is recognized as a fruitful soil for scientific communities, because of its rapidity, diversity and possibilities of new forms of interaction. The development of sites of social bookmarks, as Connotea's, allows researchers to manage information on the Internet, organizing and sharing references with their scientific peers. We analyze this site, which has a social character and presents itself as a new informal space for information sharing, group creation and proprietary libraries construction by using keywords. Also, we approach scientific communities concepts, social bookmarks and Folksonomy. We consider that Connotea reproduces some common behaviors of scientific communities and allows the interchange among different areas of knowledge.
\end{abstract}

\section{Keywords:}

Scientific Community. Social Bookmarks. Folksonomy. Connotea. 


\section{INTRODUÇÃO}

Com o desenvolvimento das tecnologias de informação e comunicação (TICs), muitos pesquisadores passaram a utilizar a Internet como meio de veiculação de seus trabalhos científicos, seja em páginas pessoais, institucionais ou revistas científicas eletrônicas. Porém, as possibilidades da tecnologia extrapolam a publicação de textos, permitindo o desenvolvimento de serviços on-line que possibilitam o compartilhamento e a troca constante de informações entre os membros das comunidades acadêmicas. A exemplo disso, constata-se a utilização de ferramentas sociais ou sites que permitem aos membros das comunidades científicas gerenciar informações na Internet, organizando e compartilhando referências com seus pares.

Essas ferramentas têm como forma de organização da informação a utilização de palavras-chave ou tags (etiquetas) atribuídas pelos sujeitos para identificar categorias ou conceitos relacionados a variados tipos de arquivos, como: artigos, fotografias, músicas, livros, sites, blogs, entre outros. Tal classificação, denominada Folksonomia, é realizada pelos próprios pesquisadores e não por profissionais da informação ou por indivíduos treinados para tal.

Este trabalho é conclusivo e faz parte de um estudo mais amplo elaborado pelo grupo de estudos em Comunicação Científica do PPGCOM/UFRGS, composto por docentes pesquisadores e alunos de mestrado e doutorado, que investiga os sistemas de recuperação de informação. Revisam-se os conceitos de social bookmarks e Folksonomia, e analisa-se o site Connotea, da Nature Group Publishing, que representa uma perspectiva acadêmica, possibilitando aos usuários organizar, compartilhar e buscar novas leituras e descobertas dentro das várias áreas do conhecimento científico. Este site, disponível desde o ano de 2005, abre um espaço informal para a colaboração entre comunidades científicas, facilitando a interação entre os pesquisadores e disseminando, de forma mais ágil, as recentes descobertas e o estado de arte da ciência.

A decisão pela escolha do Connotea, deve-se à notoriedade da instituição responsável pelo site. A Nature Group Publishing é uma empresa produtora de publicações científicas, entre elas o periódico Nature, que é conhecido mundialmente pela comunidade científica. A análise foi realizada através das seções do site denominadas: 
Home, Latest News, About Connotea, Site Guide e Community Pages, mais o quadro dos menus: Explore, Beginner's Guide, Account Details, Help e Advanced, da segunda semana do mês de julho à primeira de agosto de 2006, sendo que neste período houve uma mudança no leiaute e disposição das informações. É necessário destacar este recorte temporal, já que os sites disponíveis na Internet podem sofrer alterações e atualizações a cada dia.

\section{COMUNIDADES CIENTÍFICAS E A COMUNICAÇÃO DO CONHECIMENTO}

As comunidades científicas têm origem no século XVII, no continente europeu, com a fundação das primeiras sociedades e academias científicas. Nessa época, o saber deixou de ser propriedade das ordens religiosas e passou a ser compartilhado com os leigos, ocasionando o aumento do número de trabalhos. Esta ruptura, lembrada por Maia (2006), é justamente a denominada Revolução Científica, que

"[. . .] envolvia a rejeição tanto da tradição clássica quanto da medieval, inclusive de uma visão de mundo baseada nas idéias de Aristóteles e Ptolomeu.” (BURKE, 2003, p. 42).

O movimento buscava agregar conhecimentos alternativos, como o dos artesãos, curandeiros, ferreiros, mestres de obras, entre outros, mas encontrava oposição em determinadas Universidades. Assim, ainda conforme Burke (2003), os indivíduos que apoiavam tal movimento organizaram-se e fundaram as primeiras sociedades, sendo a primeira a Academia del Cimento, na cidade de Florença (1657), depois a Royal Society, em Londres (1660), e a Royale des Sciences, em Paris (1666).

Meadows (1999) indica que as sociedades científicas foram sendo criadas de forma lenta e gradual, mas no século XVIII seu número aumentou rapidamente, chegando a se estabelecer em torno de 70 academias ou sociedades oficialmente consagradas. O crescimento do número das sociedades e academias demonstra que os estudiosos e pesquisadores vislumbraram novas formas de reunir os pares e discutir temas científicos.

Também, nessas academias “[. . .] começaram a ser difundidos textos voltados para educação e divulgação científica.” (MAIA, 2006, p.46). As revistas científicas, criadas no século XVII com o surgimento das primeiras sociedades, passaram a coexistir com as trocas de cartas, livros e a comunicação oral.

(c) Revista Digital de Biblioteconomia e Ciência da Informação,Campinas, v.5, n. 1, p. 77-94, jul/dez. 2007- ISSN: 1678-765X. 
Cada comunidade científica possui características próprias, no que se refere às formas de investigar, publicar e comunicar suas pesquisas. Para Targino (2000, p. 54) o termo comunidade cientifica designa:

[. . . ] tanto a totalidade dos indivíduos que se dedicam à pesquisa cientifica e tecnológica como grupos específicos de cientistas, segmentados em função das especialidades, e até mesmo de línguas, nações e ideologias políticas. No entanto, sempre, os membros de uma comunidade científica compartilham dos mesmos paradigmas [...].

O vocabulário especializado, o paradigma seguido e as metodologias empregadas são algumas das particularidades que identificam as comunidades científicas e permitem o compartilhamento de informações entre seus membros e uma comunicação mais eficaz.

Atualmente, as TICs influenciam a comunicação do conhecimento científico, como ocorre em outros setores da sociedade, introduzindo novas formas de interação, como correio eletrônico, listas de discussão, videoconferências, fóruns eletrônicos, páginas pessoais e institucionais, blogs, entre outras. Desta maneira, a Internet potencializou os processos de comunicação informal e formal que já ocorriam, e ainda ocorrem, no ambiente tradicional, criando novos fluxos e trocas de informação entre os integrantes das comunidades científicas.

O uso dessas tecnologias fez surgir uma nova configuração de comunidades científicas, baseadas nas redes eletrônicas. Para Oliveira e Noronha (2005), a comunicação informal possibilita o contato entre pesquisadores, permitindo a troca rápida de informações e o feedback imediato ao desenvolvimento das pesquisas. Os cientistas e pesquisadores, conectados através da Internet, passaram a se conhecer, interagir, pesquisar e produzir conhecimentos a distância, ainda que nunca tenham compartilhado do mesmo espaço físico.

Côrrea (2005), ao estudar a lista de discussão ABRH-Gestão, comprova que o ciberespaço promove o convívio social, além de provocar a disputa e a cooperação numa comunidade virtual de caráter científico. As discussões e debates podem ocorrer em tempo assíncrono ou síncrono, através da tela dos seus computadores pessoais. Os recursos eletrônicos aplicados ao desenvolvimento da interatividade na comunicação científica indicam que estes recursos possibilitam a ampliação na participação de pesquisadores em colégios invisíveis, a construção cooperativa através da autoria coletiva 
e a troca de informações através do contato entre pesquisadores, interligando pessoas com os mesmos interesses formando redes (OLIVEIRA; NORONHA, 2005). Além disso, a Internet também diminuiu o tempo de publicação dos trabalhos científicos, ao tornar alguns processos de editoração mais rápidos, permitindo, até mesmo, que o autor seja seu próprio editor.

Uma nova aplicação das TICs são os sites que permitem aos pesquisadores organizarem e compartilharem suas referências ou leituras. Para isso, os pesquisadores utilizam um vocabulário comum e próprio aos seus pares, também usuários destes sites.

\section{SOCIAL BOOKMARKS}

Hammond et al. (2005) apontam que social bookmarks são uma das aplicações possíveis dos softwares sociais. Entre outras aplicações, pode-se citar os blogs, páginas Wiki, redes eletrônicas sociais ou comunitárias. Segundo os autores, quando os links são etiquetados, gerenciados, comentados e publicados na Internet, passam a representar a biblioteca particular do usuário colocada em espaço público. Quando agregada com as bibliotecas de outros usuários, possibilitará o estabelecimento de redes sociais. Assim, ao utilizar gerenciadores de social bookmarks qualquer sujeito permite que os seus links favoritos sejam vistos e compartilhados por outros usuários, formando coleções maiores, que não seriam possíveis sem a utilização da interface da Internet. Essas aplicações são como uma nova classe emergente de ferramentas que tem como uma de suas características mais marcantes a Folksonomia (HAMMOND et al., 2005).

Com o uso de um vocabulário comum, criado pela Folksonomia, o usuário pode ter acesso a uma identificação do documento, facilitando sua recuperação em um processo de busca. O usuário, também, é livre para navegar nas palavras-chave fornecidas por outros usuários que sejam similares as suas, ou que lhe despertem algum interesse. Autores como Lund et al. (2005) consideram que essas aplicações da Internet, para gerenciamento público de links, atendem as necessidades da comunidade científica.

Na Internet encontram-se exemplos desses serviços como: del.icio.us (http://del.icio.us/) e Furl (http://www.furl.net/) para organização e armazenamento de páginas da Internet; Flickr (http://www.flickr.com/) para gerenciamento e compartilhamento de fotografias;

(c) Revista Digital de Biblioteconomia e Ciência da Informação,Campinas, v.5, n. 1, p. 77-94, jul/dez. 2007- ISSN: 1678-765X. 
Technorati (http://www.technorati.com/) para recuperação de informações no mundo dos blogs. Todos esses sites são de livre acesso e podem ser utilizados pelo público em geral. Entre os sites que têm como público-alvo comunidades científicas, pode-se citar o CiteULike (http://www.citeulike.org/) e o Connotea (http://www.connotea.org/). Os dois sites são serviços gratuitos para os pesquisadores organizarem e compartilharem suas referências. Pode-se destacar algumas particularidades do CiteULike, como: apresenta a página em nove idiomas, permite a formação de grupos, lista os números recentes de alguns periódicos científicos, entre outras. Especificamente sobre o Connotea, Lund et al. (2005), em um estudo de caso da ferramenta, apresentam suas características e uma visão geral do serviço. Os autores destacam quatro conceitos-chave que formam a base do Connotea:

a) armazenamento on-line de referências e bookmarks: o usuário passa a ter uma base de dados de citações que pode ser acessada e manipulada em seu computador ou em qualquer outro. Como desvantagens citam a possível dificuldade de uso e a exposição dos dados do usuário a outros;

b) organização simples e não-hierárquica: os dados podem ser recuperados por meio das palavras-chave, usuários ou links. Esse sistema, como é baseado na interface da Internet, permite uma fácil navegação;

c) acesso aberto à lista dos outros usuários: cada bookmark incluído no Connotea pode ser acessado por usuários registrados ou não, possibilitando uma conexão entre os membros. O principal benefício do acesso aberto é os muitos usuários armazenarem seus bookmarks num só local facilitando a navegação;

d) recuperação de informações bibliográficas: o Connotea descobre e importa informações sobre os artigos ou livros que foram armazenados no site

O Connotea é um social bookmarks, que seguiu alguns padrões estabelecidos por seus antecessores, porém adaptou e criou outros recursos visando a atender às necessidades do público acadêmico.

(c) Revista Digital de Biblioteconomia e Ciência da Informação,Campinas, v.5, n. 1, p. 77-94, jul/dez. 2007- ISSN: 1678-765X. 


\section{FOLKSONOMIA}

O termo Folksonomia, criado pelo arquiteto de informação Thomas Vander Wal, é uma tradução do inglês - Folksonomy - junção das palavras folk (povo, gente) e Taxonomy (Taxonomia). Mathes (2004) aponta que a Folksonomia seria a terceira abordagem para a classificação da informação. A primeira delas é a classificação desempenhada pelos catalogadores e bibliotecários, que requer educação especializada e controle de vocabulário. A segunda abordagem refere-se ao momento em que o autor cria seus próprios metadados em alternativa aos metadados criados pelos profissionais especializados. A Folksonomia, por outro lado, caracteriza-se por ser uma classificação social, ou seja, um trabalho realizado coletivamente por usuários das ferramentas ou sites, que organizam as informações atribuindo palavras-chave a textos, artigos, livros, fotografias, vídeos, músicas, links, entre outros, disponíveis na Internet.

Assim, a Folksonomia significa, nas palavras de Quintarelli (2005) ${ }^{1}$, que "O poder é do povo.”, ou seja, o sujeito decide como irá representar e recuperar a informação através de sua própria linguagem. Em oposição aos esquemas de classificação, que são hierarquias rígidas, e aos tesauros, a Folksonomia não tem nenhuma preocupação com o controle e padronização do vocabulário. Justamente por essa deficiência, ela não pode ser aplicada a todos os contextos de organização da informação. Mathes (2004) indica alguns problemas que acompanham a Folksonomia, como: a falta de controle de acrônimos e sinônimos, a ambigüidade dos termos, e a diversidade de representação de palavras compostas (com espaço ou sem espaço entre elas). Há que se destacar, ainda, a falta de controle de homógrafos e de palavras no plural ou singular. Apesar dessas limitações, ela apresenta alguns aspectos vantajosos, entre eles a possibilidade de fazer descobertas inesperadas, a utilização do vocabulário próprio dos usuários, a auto-expressão de um grupo, as possibilidades de agregação e compartilhamento de etiquetas, a liberdade para criar comunidades (MATHES, 2004; QUINTARELLI, 2005).

Os sites que utilizam a Folksonomia parecem proliferar na Internet, cada vez mais, e talvez os aspectos desvantajosos possam ser superados, a fim de diminuir a desordem e oferecer serviços de mais qualidade aos usuários. O que deve ser destacado nessa

\footnotetext{
${ }^{1}$ Documento eletrônico não paginado.
}

(c) Revista Digital de Biblioteconomia e Ciência da Informação,Campinas, v.5, n. 1, p. 77-94, jul/dez. 2007- ISSN: 1678-765X. 
classificação é que nada está pré-determinado, o usuário atribui espontaneamente os rótulos aos documentos ou links que deseja organizar. Desta maneira, a Folksonomia coexistirá com a tradicional Taxonomia, sem pretender a sua substituição.

\section{CONNOTEA}

A noção de comunidade “[. . . ] está sempre ligada à idéia de um espaço de partilha, a uma sensação, a um sentimento de pertencimento, de inter-relacionamento íntimo a determinado agrupamento social.” (LEMOS, 2002, p. 153). Baseando-se nisso justificase a descrição e analise do Connotea, um social bookmark que se constitui um espaço para partilha de informações relevantes e relacionamento entre os pares. Segue o estudo feito acerca do site.

Na seção Home, ou página inicial (Figura 1), o Connotea apresenta os seguintes comandos: Organise. Share. Discover. (Organize. Compartilhe. Descubra.), demonstrando claramente seus objetivos de colaboração e compartilhamento do conhecimento entre os pares. Desenvolvido pela Nature Group Publishing destina-se a organizar referências e páginas da Internet que os acadêmicos desejam armazenar e compartilhar com outros usuários, podendo ser acessadas de qualquer computador, desde que conectado à Internet. Ao encontrar artigos ou links de interesse, o pesquisador salvaos no Connotea e adiciona palavras-chave para sua posterior recuperação. Ainda, na página inicial, podem ser acessadas as principais seções do Connotea e um quadro de menus, facilitando a navegabilidade.

Através de um registro, os usuários criam uma conta (nome do usuário e senha) para o gerenciamento de sua biblioteca particular. Contudo, sem precisar possuir um login, qualquer visitante do site pode acessar os links referenciados das bibliotecas de cada usuário. Ressalta-se que o Connotea facilita o registro, sendo necessário apenas cadastrar o nome, e não outras informações pessoais como geralmente acontece nos sites da Internet. 
Figura 1 - Página Inicial do Connotea

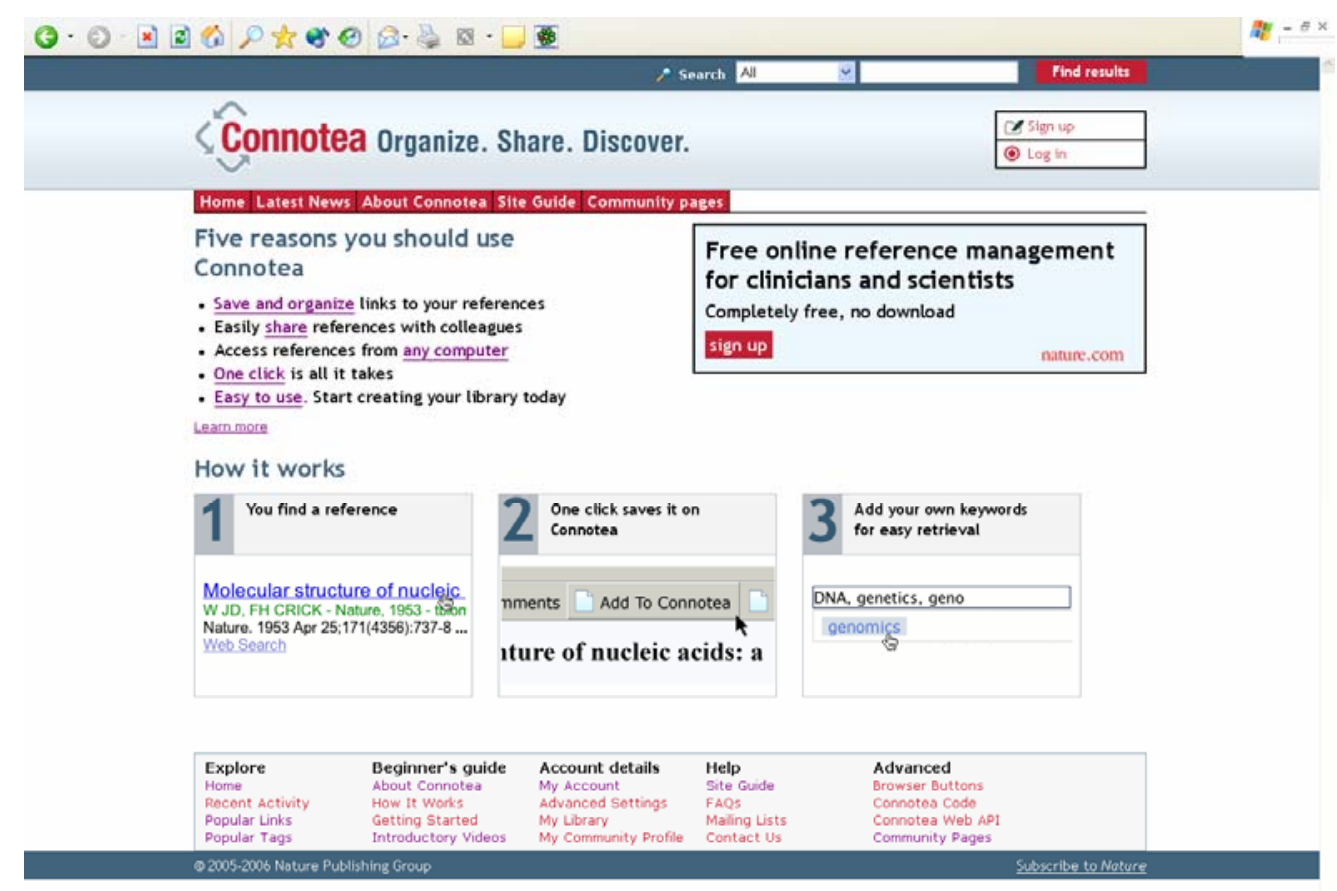

Fonte: http://www.connotea.org/

Na seção Latest News podem ser encontradas as notícias mais recentes e as atualizações do site, sendo que a postagem é realizada somente pelo Connotea. Quanto à seção About Connotea, encontram-se informações gerais e o propósito do site. Com base no del.icio.us, esse serviço público e gratuito procurou agregar novas funções destinadas à comunidade acadêmica. Cada pesquisador pode optar em compartilhar sua biblioteca com todos os usuários do Connotea ou apenas um grupo de colegas, e ainda pode optar em torná-la totalmente privada. Isso reflete comportamentos de pesquisa dos indivíduos.

Enquanto alguns optam por abrir as "portas” de sua biblioteca para contribuir com as buscas dos seus pares, outros preferem limitar o acesso a sua coleção, mantendo informações que consideram importantes em caráter privado.

Na seção Site Guide são apresentadas as características do Connotea e informações sobre seu funcionamento. Cada recurso oferecido é explicado passo a passo e, algumas vezes, com ilustrações das páginas do próprio site. O Connotea demonstra preocupação com a educação dos usuários iniciantes, disponibilizando três vídeos informativos, sendo que cada vídeo possui um narrador e legendas da fala do mesmo (não são traduções, mas o 
texto narrado). Essa preocupação com os usuários é de grande valia, já que nem todos os pesquisadores conhecem ou utilizam social bookmarks. Através dos vídeos os usuários aprendem, por si próprios, como utilizar esse serviço e constroem seu conhecimento.

O Connotea possibilita três formas de adicionar artigos, a saber: Bookmarklet - é um programa, que fica na lista de favoritos (bookmarks) do browser do usuário; Add form (formulário de inclusão) - é uma maneira de adicionar manualmente os artigos, bastando o usuário copiar a URL (Uniform Resource Locater) no momento do preenchimento do formulário e, depois, adicionar à sua biblioteca; Digital Object Identifiers (DOIs) - o Connotea reconhece e armazena o DOI diretamente, convertendo-o em um link. Nota-se que o site oferece possibilidades para que os usuários escolham o que consideram mais fácil na construção e gerenciamento de sua coleção.

Os usuários podem salvar qualquer página da Internet, sendo que o Connotea adiciona automaticamente informações bibliográficas de páginas salvas de fontes como: Nature, PubMed, Science, Blackwell Synergy, Wiley Interscience, Amazon, entre outras. A adição automática dessas informações facilita a tarefa do pesquisador, na medida em que ele não necessita despender de seu tempo para inserir dados. Vale destacar que não há limite no número de referências ou páginas da Internet que podem ser armazenadas, ou seja, os usuários têm liberdade para construir sua coleção sem preocupação com o "espaço” disponível. As tarefas administrativas podem ser facilitadas pelo uso do toolbox (caixa de ferramentas) que permite editar a própria biblioteca, elaborar notas para as palavraschave, criar grupos e importar ou exportar a lista de bookmarks.

O site permite, também, excluir, copiar e salvar as referências de outros usuários, para a própria biblioteca. Caso um artigo tenha sido salvo por mais de uma pessoa, o sistema cria um link que indica o número de usuários que salvou aquele artigo. Desta maneira, este número pode ser uma indicação do interesse da comunidade científica pelo artigo.

Mais um recurso disponível é a adição e visualização de comentários que os usuários escrevem para suas próprias referências. Essa é uma forma de trocar informações entre os pares, dar créditos ao artigo ou página da Internet, indicar leituras e elaborar críticas.

(c) Revista Digital de Biblioteconomia e Ciência da Informação,Campinas, v.5, n. 1, p. 77-94, jul/dez. 2007- ISSN: 1678-765X. 
Também, os usuários que formarem uma lista com artigos sob determinado nome poderão criar uma nota explicativa referente a esta lista. Esse recurso pode interessar aos pares, pois permite que os artigos já salvos na biblioteca particular de um colega sejam vistos e, conseqüentemente, compartilhados. Portanto, o Connotea parece assumir uma das funções das listas de referências que aparecem nos artigos científicos e demais trabalhos acadêmicos, ou seja, descobrir textos adicionais para leitura.

Para a ordenação da coleção de favoritos, os usuários empregam a Folksonomia, ou seja, uma organização simples e não-hierárquica como destacam Lund et al. (2005). O site explica como adicionar ou renomear as palavras-chave, sendo que o usuário tem liberdade para adicionar aquelas que considera mais representativas do assunto, utilizando seu próprio vocabulário. Além de criar palavras-chave, o Connotea possibilita elaborar notas para as mesmas, esclarecendo seu significado. Este recurso é bastante útil para definir um termo ou explicar aquele que está em fase de construção/verbalização (constructo), ou ainda, ajuda aqueles colegas que não são da mesma área do conhecimento, mas têm interesse no tema.

Ainda na seção Site Guide, o Connotea apresenta as regras do seu mecanismo de recuperação da informação. Tal mecanismo possibilita pesquisar na biblioteca pessoal, em todos os registros públicos ou no Google (recupera apenas links armazenados no Connotea), podendo recuperar pela palavra-chave exata ou pelo nome exato do usuário, não sendo possível a utilização de operadores booleanos. Outra forma de recuperar informação é editando a URL do site através da inserção dos nomes dos usuários, das palavras-chave ou unindo as duas formas. Para a edição da URL do Connotea, utilizam-se os sinais de “+” (and) e “/” (or). Este recurso certamente propicia ao usuário fazer buscas rápidas e obter informações mais específicas, desde que saiba os termos exatos.

A importação de uma remessa de referências para a própria biblioteca dos usuários é mais um recurso oferecido pelo site. Além de importar, o site permite ao usuário exportar referências ou sua lista completa para o EndNote ${ }^{2}$ ou outro gerenciador. Exportar uma lista inteira ao invés de uma referência por vez, torna a tarefa mais rápida para os pesquisadores que podem trocar maior volume de informações com seus pares.

\footnotetext{
${ }^{2}$ Software para pesquisa de bases de dados bibliográficas on-line, criação de bibliografias e organização de referências, imagens e PDFs.
}

(c) Revista Digital de Biblioteconomia e Ciência da Informação,Campinas, v.5, n. 1, p. 77-94, jul/dez. 2007- ISSN: 1678-765X. 
A formação de grupos (Figura 2) neste ambiente eletrônico é um recurso que merece destaque nesta análise. Os grupos apresentam-se como uma forma de saber o que os colegas estão lendo e também possibilitar elos de cooperação para construir coleções de artigos e páginas da Internet. Podem ser criados grupos públicos ou privados. Se os grupos são públicos, o usuário pode navegar pelas páginas dos mesmos, mas não editar porque isso só é permitido aos membros dos grupos. Nos grupos privados, porém, somente os seus integrantes têm conhecimento da sua existência. Um grupo é considerado propriedade de quem o criou e este pode convidar ou remover membros.

Uma desvantagem desse recurso é que, atualmente, não há maneira de solicitar inclusão em um determinado grupo público, a não ser que o mesmo disponibilize seu endereço eletrônico para contato ou demonstre interesse em incluir novos membros.

Figura 2 - Página da Lista de Grupos

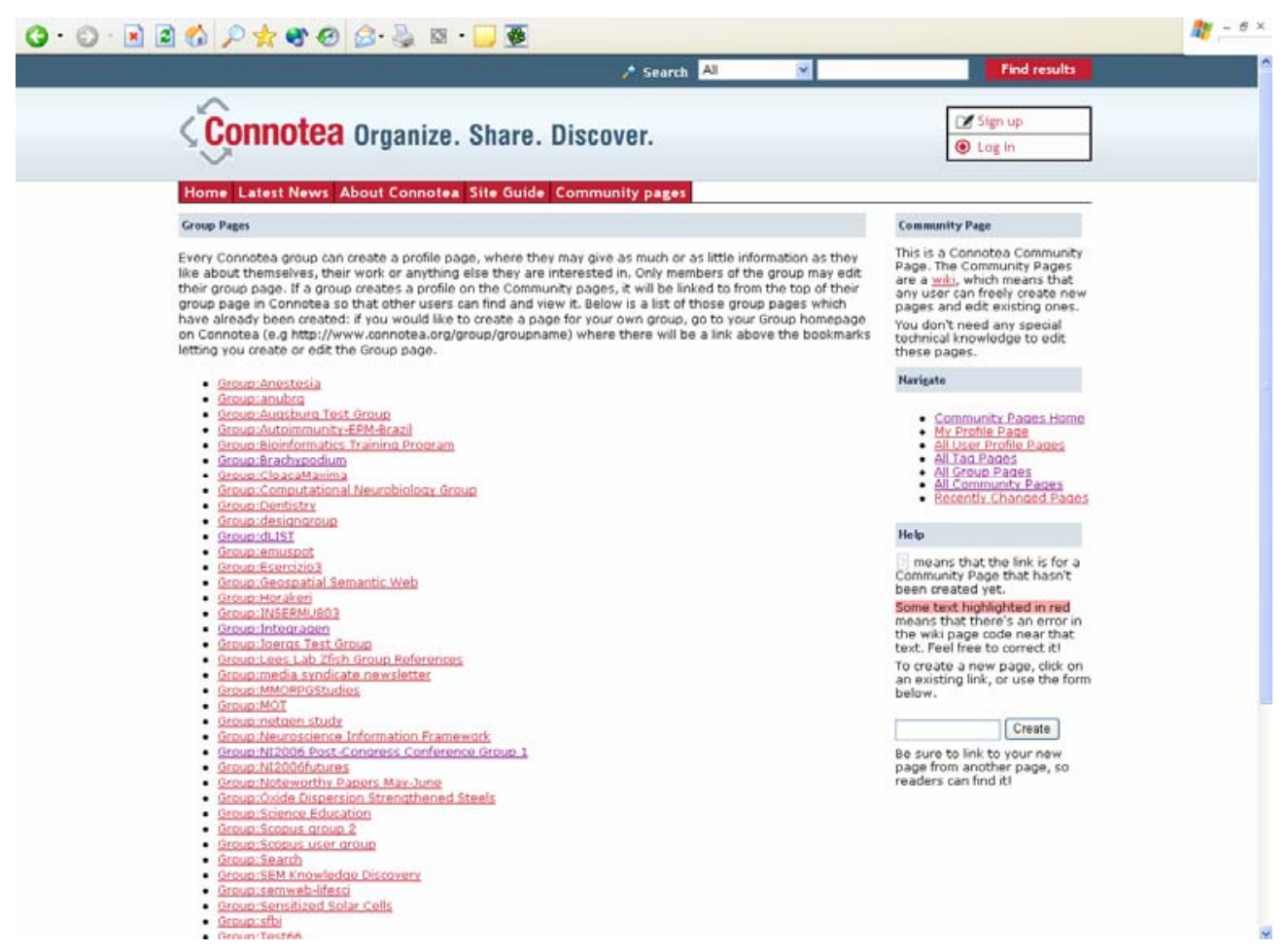

Fonte: http://www.connotea.org/wiki/Generate:PageList?prefix=Group

Entre todos os recursos oferecidos, talvez a permissão para criar grupos esteja entre os mais importantes, porque os pesquisadores, neste ambiente eletrônico, podem compartilhar dos mesmos interesses e efetivar trocas significativas de informação, como ocorre nos ambientes tradicionais. A formação de grupos é uma das características da 
natureza social do Connotea, pois os grupos previamente existentes poderão fazer uso deste novo ambiente agregador, enquanto novos colégios invisíveis poderão formar-se em vista das descobertas feitas dentro do próprio site. Price (1976, p. 45) observa a importância de tais agregações sociais ao escrever sobre a formação de um pesquisador, “Se este cientista permanece num campo em que ele é o único expoente, não lerá nada além de seus próprios trabalhos.” O autor destaca que dentro de um grupo maior é muito provável o aparecimento de formações menores e relativamente isoladas.

Durante o período de consulta e análise, o Connotea possuía 42 grupos públicos. O número de grupos privados foi impossível de ser estabelecido, uma vez que não são visíveis a todos os usuários. Apenas 19 grupos possuíam algumas informações, como: descrição do grupo, objetivos, nomes dos integrantes, endereços dos sites das suas instituições e para contato, convite para participar do grupo, entre outras. Aparentemente eles se encontravam em fase de construção, conforme pôde ser observado pelas datas recentes de criação. Desta maneira, só com o passar do tempo será possível fazer uma análise mais completa do uso do Connotea pelos pesquisadores, no que se refere à formação de grupos. Vale destacar que a criação de grupos fechados é um reflexo do que ocorre na própria ciência, já que a maioria dos pesquisadores somente comunica informações de suas investigações para seus pares quando há resultados, pois eles buscam o registro da autoridade, o ineditismo e a originalidade das descobertas. A cerca disso Price (1976, p. 53) observa que

“[. . .] existe um limite para um grupo funcional e, se um número excessivo for convidado, acabar-se-ia criando um subgrupo extra-oficial de participantes realmente conhecedores do assunto.”

A última seção, denominada Community Pages, é baseada em páginas wiki. Elaborada apenas para usuários registrados, permite incluir páginas sobre o próprio Connotea, palavras-chave, grupos, FAQs, perfil de um usuário, entre outras, sendo que para a edição do texto, o site fornece ajuda com algumas regras e formatos de texto. Percebe-se que com o uso das propriedades das páginas wiki, o Connotea abre espaços para que as comunidades científicas construam de forma coletiva suas páginas de interesse, escrevendo sobre elas mesmas e sobre outros temas.

No menu Explore, o Connotea fornece acesso direto às atividades recentes no site, bem como, à lista das palavras-chave mais utilizadas e dos artigos ou links mais populares. Ao 
clicar em qualquer palavra-chave, a mesma remete a uma lista de referências que possuem a mesma palavra-chave utilizada para descrever o assunto. Assim, todas essas listas de usuários e palavras-chave servem como ponto de partida para os pesquisadores encontrarem leituras e novidades na sua área de interesse, assim como encontrar outros pesquisadores com interesses similares.

O Connotea elaborou o menu Beginner's Guide para os usuários iniciantes, a fim de indicar os passos necessários para a adição e organização das referências da biblioteca particular de modo simples e com linguagem clara. No menu Account Details, o site dispõe os atalhos para criação de uma conta, inclusão do endereço da OpenURL e login para a própria biblioteca ou para o perfil da comunidade criada.

Para os usuários que possuem dúvidas, o Connotea criou o menu Help com as FAQs (Frequently Asked Questions). Além das FAQs, o Connotea fornece o endereço do seu correio eletrônico para contato direto e criou, também, uma lista de discussão para o usuário associar-se. Desta forma, através da lista ou do correio eletrônico, os usuários poderão encontrar respostas, sanar dúvidas que os textos explicativos não deixam suficientemente claro e, até mesmo, postar comentários referentes ao site.

No menu Advanced os usuários interessados na programação do site têm acesso a informações do código do Connotea, tanto aos membros registrados como para os visitantes. O site disponibiliza, também, a API (Application Programming Interface) do software, possibilitando ao usuário programador construir softwares e aplicativos utilizando características do Connotea.

Vale destacar ainda a importância da manipulação dos recursos e da organização da informação on-line pela comunidade científica no Connotea. Diferentemente de algumas páginas estáticas da Internet, surge neste momento uma nova geração de softwares que obtêm sucesso justamente pela adesão e participação cooperativa de indivíduos com interesses pessoais de pesquisa, assim como de compartilhamento de suas referências e descobertas.

O site expressa também a segmentação das comunidades científicas em função das especialidades, conforme aponta Targino (2000). Independentemente da segmentação das 
comunidades de pesquisadores do site, nada impede a um pesquisador participar de mais de um grupo de interesse. O Connotea possui grupos de várias áreas do conhecimento. Para Oliveira e Noronha (2005) o uso de recursos eletrônicos para a comunicação científica possibilita a participação de pesquisadores em colégios invisíveis e a troca de informações. Assim, o Connotea é um site que reúne os pares e cria novos fluxos para o compartilhamento de informações através do contato informal e da troca de documentos formais.

\section{CONSIDERAÇÕES FINAIS}

Um site como o Connotea, para comunidades científicas em todas as áreas do conhecimento, significa novas formas de comunicar, interagir, compartilhar e demonstrar interesses de estudo. Neste ambiente eletrônico e informal, as bibliotecas pessoais passam a ser públicas (desde que seja o desejo do criador), e os pesquisadores, por meio do seu vocabulário próprio e da sua coleção, passam a influenciar e sofrer influências dos colegas. Segundo Price (1976) o pesquisador, em determinado momento da pesquisa, irá encontrar outros seguindo as mesmas linhas com a mesma formação teórica básica, examinando os mesmos problemas. Este pesquisador, segundo o autor, deverá querer assimilar o trabalho de seus pares. Seja ao integrar um grupo ou ao navegar pelas palavras-chave e bibliotecas alheias, o Connotea permite ao pesquisador descobrir novos trajetos em suas pesquisas e estabelecer novas formas de interação com seus pares.

Se no passado, conforme indica Meadows (1999), as comunidades científicas se formavam de maneira lenta e gradual, hoje, com o uso das tecnologias e de softwares como o Connotea, esta formação pode ocorrer de uma forma mais rápida, como requer o mundo de hoje.

Ao possibilitar a organização das referências de interesse totalmente individual num só local, facilita a navegação pela Internet, já que os pesquisadores não precisam acessar vários sites para realizar suas leituras e consultas à literatura científica. Além de tudo, o Connotea permite o intercâmbio interdisciplinar, ao não direcionar o site a apenas uma das diferentes áreas do conhecimento. Portanto, como destaca Lund et al. (2005), os social bookmarks satisfazem as necessidades do mundo científico. Essas necessidades podem ser tanto informacionais quanto sociais ou de compartilhamento.

(C) Revista Digital de Biblioteconomia e Ciência da Informação,Campinas, v.5, n. 1, p. 77-94, jul/dez. 2007-ISSN: 1678-765X. 
Outro ponto a ser assinalado é que o Connotea está disponível em apenas um idioma, o inglês. Essa característica talvez restrinja o seu uso por um número maior de sujeitos. Indica-se, como sugestão, a disponibilização do site em outros idiomas, a fim de atender um grupo maior de usuários. Ainda, considera-se que a navegação do site obteve melhorias com as mudanças no leiaute, ao incluir atalhos para as diversas seções e menus.

A natureza social deste site pode ser considerada sua principal característica, um reflexo da própria Internet, que vem sendo inundada com sites voltados a intervenção e edição do conteúdo pelos seus usuários. A utilização do Connotea pela comunidade científica vem a demonstrar que estes recursos podem ser mais um espaço para a comunicação científica. Dispõe aos pesquisadores a possibilidade deles mesmos organizarem suas informações, através de palavras-chave, de acordo com suas estruturas cognitivas, e também, oferece a oportunidade de se expressarem enquanto sujeitos por meio de sua linguagem.

Concluí-se que alguns comportamentos comuns da comunidade científica se reproduzem no Connotea a exemplo da construção de bibliotecas privadas e da formação de colégios invisíveis. Estes são integrados apenas por pares convidados pelo seu criador, a fim de que possam contribuir para os interesses do mesmo. Price (1976) aponta a necessidade de criar condições de interação entre cientistas de alto nível, mantendo condições para que material pertinente seja consultado e facilitando a reunião e condensação do material científico mais importante. Pode-se perceber nessas configurações que se estabelecem no Connotea a contínua busca por originalidade, exclusividade e autoridade das comunidades científicas.

\section{REFERÊNCIAS}

BURKE, Peter. Uma história social do conhecimento: de Gutenberg a Diderot. Rio de Janeiro: Jorge Zahar, 2003.

\section{CÔRREA, Cynthia Harumy Hatanabe. Interação social da comunidade científica no} ciberespaço: estudo da lista de discussão ABRH-Gestão. 2005. 120 f. (Dissertação) Mestrado em Comunicação e Informação, Universidade Federal do Rio Grande do Sul, Porto Alegre, 2005.

(c) Revista Digital de Biblioteconomia e Ciência da Informação,Campinas, v.5, n. 1, p. 77-94, jul/dez. 2007- ISSN: 1678-765X. 
HAMMOND, Tony et al. Social bookmarking tools (I): a general review. D-Lib Magazine, Reston, v. 11, n. 4, Apr. 2005. Disponível em:

http://www.dlib.org/dlib/april05/hammond/04hammond.html>. Acesso em: 9 jul. 2006.

LEMOS, André. Cibercultura: tecnologia e vida social na cultura contemporânea. 2. ed. Porto Alegre: Sulina, 2004.

LUND, Bem et al. Social bookmarking tools (II): a case study - Connotea. D-Lib Magazine, Reston, v. 11, n. 4, Apr. 2005. Disponível em:

<http://www.dlib.org/dlib/april05/lund/04lund.html>. Acesso em: 14 jul. 2006.

MAIA, Maria de Fátima Santos. A produção e o uso de informação em saúde: estudo bibliométrico da área de Epidemiologia. 2006. 118 p. (Dissertação) - Mestrado em Comunicação e Informação, Universidade Federal do Rio Grande do Sul, Porto Alegre, 2006.

MATHES, Adam. Folksonomies : cooperative classification and communication through shared metadata. 2004. Disponível em:

$<$ http://www.adammathes.com/academic/computer-mediatedcommunication/folksonomies.pdf>. Acesso em: 5 jun. 2006.

MEADOWS, Arthur Jack. A comunicação científica. Brasília, DF: Briquet de Lemos/Livros, 1999.

OLIVEIRA, Érica Beatriz Pinto Moreschi de; NORONHA, Daisy Pires. A comunicação científica e o meio digital. Informação \& Sociedade: estudos, João Pessoa, v. 15, n. 1, p. 1-15, 2005. Disponível em:

http://www.informacaoesociedade.ufpb.br/ojs2/index.php/ies/article/viewFile/53/51.

Acesso em: 7 jun. 2006.

PRICE, Derek J. de Solla. O desenvolvimento da ciência: análise histórica, filosófica, sociológica e econômica. Rio de Janeiro: Livros Técnicos e Científicos, 1976.

QUINTARELLI, Emanuele. Folksonomies: power to the people. In: INCONTRO ISKO ITALIA - UNIMIB, 2005, Milan. Disponível em: http://www.iskoi.org/doc/folksonomies.htm. Acesso em: 15 jul. 2006. 
TARGINO, Maria das Graças. Comunicação cientifica: uma revisão de seus elementos básicos. Informação \& Sociedade: estudos, João Pessoa, v. 10, n. 2, p. 37-85, 2000.

\section{Cleusa Pavan}

Bacharel em Biblioteconomia. Mestranda em Comunicação e Informação do PPGCOM/UFRGS. cleusapavan@yahoo.com.br

\section{Geórgia Geogletti Cordeiro Dantas}

Bacharel em Biblioteconomia. Mestranda em Comunicação e Informação do PPGCOM/UFRGS. georgiagcd@gmail.com

\section{Ida Regina C. Stumpf}

Doutora em Comunicação e professora do PPGCOM/UFRGS. Pesquisadora CNPq. irstumpf@ufrgs.br

\section{Sônia Elisa Caregnato}

Doutora em Ciências da Informação e professora do PPGCOM/UFRGS.

sonia.caregnato@ufrgs.br

\section{Recebido em: 30/10/2006}

Aceito para publicação em: jan. 2007 